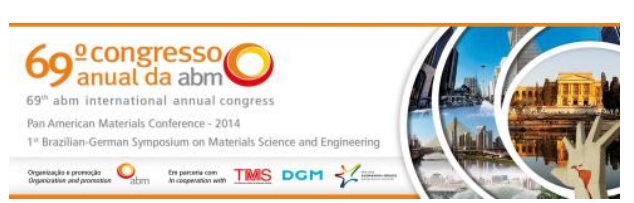

Tema: Soldagem

\title{
INFLUÊNCIA DA COMPOSIÇÃO QUÍMICA NAS PROPRIEDADES MECÂNICAS DE METAIS DE SOLDA DE ALTA RESISTÊNCIA*
}

\author{
Jorge Luiz Soares do Couto \\ Jorge Carlos Ferreira Jorge ${ }^{2}$ \\ Luís Felipe Guimarães de Souza²
}

\begin{abstract}
Resumo
O presente trabalho tem como objetivo realizar uma análise comparativa do comportamento de quatro metais de solda obtidos pelo processo arame tubular de forma a avaliar o efeito da relação $\mathrm{Ni}-\mathrm{Mn}$ nas propriedades mecânicas. Foram soldadas juntas multipasse, com consumíveis da classe $110 \mathrm{ksi}$ de resistência mecânica, preaquecimento de $200^{\circ} \mathrm{C}$, corrente contínua e posição plana e aporte térmico nominal de $1,2 \mathrm{~kJ} / \mathrm{mm}$. Após a soldagem, realizaram-se ensaios mecânicos e metalográficos em corpos-de-prova retirados integralmente do metal depositado, na condição de como soldado e após tratamento térmico pós-soldagem. Os resultados mostraram que as melhores propriedades mecânicas foram obtidas para uma composição contendo 1,35\%Mn e 2,50\%Ni. Adicionalmente, verificou-se que o tratamento térmico pós-soldagem propiciou uma redução da tenacidade ao impacto dos metais de solda de maior resistência devido à precipitação de carbetos nos contornos de grão.
\end{abstract}

Palavras-chave: Metal de solda; Tenacidade ao impacto; Tratamento térmico póssoldagem; Processo arame tubular.

\section{INFLUENCE OF CHEMICAL COMPOSITION ON THE MECHANICAL PROPERTIES OF HIGH STRENGTH STEEL WELD METALS}

\section{Abstract}

A comparative behaviour of four high strength steel weld metals obtained by FCAW process was investigated in order to evaluate the effect of chemical composition, particularly the elements $\mathrm{Ni}$ and $\mathrm{Mn}$, on the mechanical properties. Welded joints were performed by FCAW process using a preheat of $200^{\circ} \mathrm{C}$, direct current, flat position and a nominal heat input of $1.2 \mathrm{~kJ} / \mathrm{mm}$. After welding, mechanical tests and metallographic examination were conducted in specimens removed integrally from the weld metal, both in as welded and heat treated conditions. The results showed that best mechanical properties were obtained for $1,35 \% \mathrm{Mn}-2,50 \% \mathrm{Ni}$ chemical composition. In addition, it was observed that the PWHT promoted a reduction on the impact toughness due to the precipitation of carbides at the grain boundaries for the weld metals with higher mechanical properties.

Keywords: Weld metal; Impact toughness; Post weld heat treatment; Flux cored arc welding process.

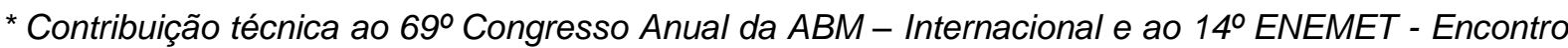
Nacional de Estudantes de Engenharia Metalúrgica, de Materiais e de Minas, 21 a 25 de julho de 2014, São Paulo, SP, Brasil.
} 


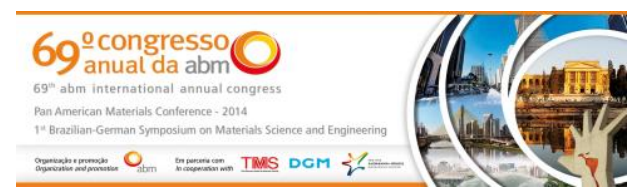

\section{INTRODUÇÃo}

A necessidade de avanço tecnológico tem exigido um elevado grau de desenvolvimento de materiais que atendam requisitos desafiadores de resistência mecânica e tenacidade. Por exemplo, para a área de exploração e produção de petróleo, existem normas específicas, tais como a norma IACS (International Association of Classification Societies) W22 [1], que definem requisitos muito severos (Tabela 1), para os quais os aços convencionais não estão aptos. Associado a este fato, deve-se destacar que as atividades offshore envolvem também operações em águas profundas e, inevitavelmente, as estruturas soldadas estarão presentes nestas aplicações. Para tanto, o desenvolvimento de materiais de alta resistência e processos que garantam maior confiabilidade com qualidade e produtividade na fabricação dos equipamentos, são fatores fundamentais para consecução dos projetos e para o sucesso das atividades da indústria brasileira, mormente quando os equipamentos se tornam cada vez maiores, e as respectivas demandas de prazos, por outro lado, são cada vez mais reduzidos.

Tabela 1. Propriedades mecânicas dos aços segundo a norma IACS W22 [1]

\begin{tabular}{c|c|c|c|c|c|c}
\hline Grau do Aço & $\begin{array}{c}\text { LE } \\
(\mathrm{MPa})\end{array}$ & LR (MPa) & Al (\%) & $\begin{array}{c}\text { RA } \\
(\%)\end{array}$ & $\begin{array}{c}\mathrm{E}_{\mathrm{cv}}(\mathrm{J}) \\
\text { Metal Base }\end{array}$ & $\begin{array}{c}\mathrm{E}_{\mathrm{cv}}(\mathrm{J}) \\
\text { Metal de solda }\end{array}$ \\
\hline R3 & 410 & 690 & 17 & 50 & 40 & 30 \\
\hline R3S & 490 & 770 & 15 & 50 & 45 & 33 \\
\hline R4 & 580 & 860 & 12 & 50 & 50 & 36 \\
\hline
\end{tabular}

Nota: LE- limite de escoamento; $L R$ - limite de resistência; $A l(\%)$ - alongamento ,

$R A(\%)$ - redução de área e $E_{c v^{-}}$energia absorvida Charpy- $V$ à $-20^{\circ} \mathrm{C}$.

Este nível de exigência torna a soldagem destes componentes um grande desafio em termos, não somente da definição do procedimento mais adequado, como principalmente, na seleção e/ou desenvolvimento de consumíveis compatíveis com a aplicação. É importante ressaltar que nestes casos, mesmo as normas de qualificação de consumíveis de soldagem, tais como AWS A 5.5 [2] , AWS 5.28 [3], AWS 5.29? e MIL-E-22200/1F [4], por exemplo, podem não atender integralmente os requisitos dos metais base utilizados nos projetos em curso [1], visto que, são limitadas à resistências mecânicas da ordem de 120ksi (830MPa) e nem sempre definem critérios de resistência ao impacto mínima, devendo os mesmos serem acordados entre fornecedor e cliente [2,3]. Apresentam ainda um outro complicador: não fazem menção à manutenção de propriedades quando se faz necessária a realização de tratamento térmico de alívio de tensões, procedimento mandatório para algumas aplicações específicas [4,5]. As normas que inserem esta exigência podem até ter requisitos inferiores para a condição de tratado termicamente [6].

Considerando este aspecto de impossibilidade de garantia de fornecimento de consumíveis com as propriedades requeridas de uma norma específica, é fundamental um estudo criterioso e investigativo para avaliar a adequação de consumíveis especiais disponíveis no mercado, ou do atendimento com confiabilidade, das requisições acordadas com os fornecedores de consuíveis.

O presente trabalho dá sequência à publicações anteriores [5,7-15], nas quais se avaliam consumíveis que sejam adequados à soldagem com requisitos desafiadores de resistência mecânica e tenacidade. Particularmente, avaliou-se o efeito do aumento do teor de $\mathrm{Mn}$ de 1,0\% para 1,4\% mantendo o teor de $\mathrm{Ni}$ em 2,5\%, e um

\footnotetext{
* Contribuição técnica ao $69^{\circ}$ Congresso Anual da ABM - Internacional e ao 14ํㅡㄹ ENEMET - Encontro Nacional de Estudantes de Engenharia Metalúrgica, de Materiais e de Minas, 21 a 25 de julho de 2014, São Paulo, SP, Brasil.
} 
último metal de solda com composição diferente do anteriores, onde se promoveu o aumento do teor de $\mathrm{Mn}$ de modo a se obter uma resistência mecânica superior.

\section{MATERIAIS E MÉTODOS}

\subsection{Materiais}

Realizou-se o estudo com quatro consumíveis, cuja composição química do metal depositado é mostrada na Tabela 2.

Tabela 2. Composição química dos metais de solda estudados (\% Peso)

\begin{tabular}{|c|c|c|c|c|c|c|c|c|c|c|c|}
\hline Metal de solda & C & $\mathrm{Si}$ & $\mathrm{P}$ & $\mathrm{S}$ & $\mathrm{Mn}$ & Mo & $\mathrm{Ni}$ & $\mathrm{Cr}$ & $\mathrm{Cu}$ & $\mathrm{V}$ & $\operatorname{Ceq}\left({ }^{*}\right)$ \\
\hline $\bar{A}$ & 0,05 & 0,31 & $\begin{array}{c}0,02 \\
0\end{array}$ & $\begin{array}{c}0,00 \\
9\end{array}$ & $\begin{array}{c}1,0 \\
9\end{array}$ & 0,51 & 2,45 & 0,03 & 0,02 & 0,01 & 0,51 \\
\hline$B$ & 0,05 & 0,41 & $\begin{array}{c}0,02 \\
1\end{array}$ & $\begin{array}{c}0,00 \\
5\end{array}$ & $\begin{array}{c}1,3 \\
2\end{array}$ & 0,52 & 2,48 & 0,02 & 0,02 & 0,01 & 0,55 \\
\hline C & 0,03 & 0,45 & $\begin{array}{c}0,01 \\
6\end{array}$ & $\begin{array}{c}0,01 \\
1\end{array}$ & $\begin{array}{c}1,3 \\
7\end{array}$ & 0,54 & 2,66 & 0,03 & 0,03 & 0,01 & 0,55 \\
\hline D & 0,07 & 0,51 & $\begin{array}{c}0,00 \\
9\end{array}$ & $\begin{array}{c}0,00 \\
9\end{array}$ & $\begin{array}{c}1,8 \\
6\end{array}$ & 0,39 & 1,68 & 0,05 & 0,03 & 0,01 & 0,58 \\
\hline
\end{tabular}

\subsection{Soldagem dos Corpos-de-Prova}

As juntas foram soldadas a partir de chapas com $19 \mathrm{~mm}$ de espessura e $700 \mathrm{~mm}$ de comprimento. A geometria e demais dimensões da junta são apresentadas na Figura 1.

As juntas foram preaquecidas à temperatura de $200^{\circ} \mathrm{C}$ e posteriormente foi realizada a soldagem multipasse, na posição plana, utilizando-se uma mistura de $75 \% \operatorname{Ar}-25 \% \mathrm{CO}_{2}$ como gás de proteção, com arames de $1,2 \mathrm{~mm}$ de diâmetro, intensidade de corrente de 260 a 290A, voltagem de 26 a 30 Volts, com aporte térmico médio de $1,2 \mathrm{~kJ} / \mathrm{mm}$, sendo realizados 20 passes de soldagem.

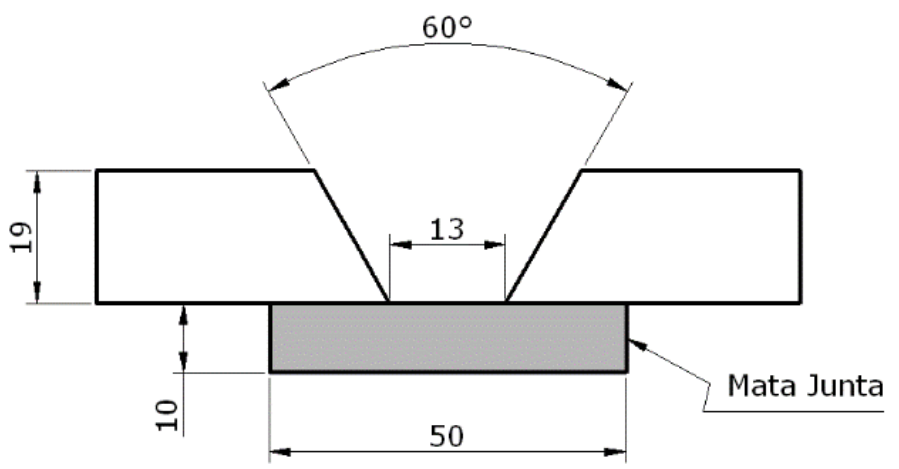

Figura 1. Detalhes da geometria da junta utilizada. Cotas em mm.

\subsection{Tratamentos Térmicos Pós Soldagem (TTPS)}

Após a soldagem, foram realizados tratamentos térmicos consistindo de aquecimento a $580^{\circ} \mathrm{C}$ por 2 horas, seguido de resfriamento ao ar, sendo esta condição comparada à condição de como soldado do metal de solda.

\footnotetext{
* Contribuição técnica ao $69^{\circ}$ Congresso Anual da ABM - Internacional e ao 14ํㅡㄹ ENEMET - Encontro Nacional de Estudantes de Engenharia Metalúrgica, de Materiais e de Minas, 21 a 25 de julho de 2014, São Paulo, SP, Brasil.
} 


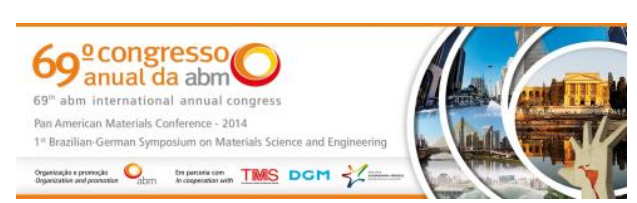

\subsection{Ensaios Mecânicos}

Foram removidos corpos-de-prova longitudinais e transversais ao cordão de solda para ensaios de tração, impacto Charpy-V e dureza.

Os ensaios de tração foram realizados à temperatura ambiente, em corpos-de-prova retirados longitudinalmente ao cordão de solda, para avaliação de todas as propriedades de tração do metal de solda, sendo realizados 2 ensaios para cada condição analisada.

Foram realizados ensaios de impacto Charpy- $\mathrm{V}$ à temperatura de $-20^{\circ} \mathrm{C}$, realizados na condição de como soldado (CS) e após TTPS. Os ensaios foram realizados em corpos-de-prova normalizados conforme a norma ASTM A-370 [16] nas dimensões de $10 \mathrm{~mm} \times 10 \mathrm{~mm} \times 55 \mathrm{~mm}$ e retirados transversalmente ao cordão de solda e à $2 \mathrm{~mm}$ da superfície da junta, sendo realizados 3 ensaios para cada condição analisada. $O$ entalhe foi posicionado no plano da espessura e no centro do cordão de solda.

Foram realizados ensaios de dureza Vickers com carga de $5 \mathrm{kgf}$. em corpos-de-prova transversais ao cordão de solda, sendo realizada uma varredura de dureza da superfície até a raiz do metal de solda em intervalos de $1,0 \mathrm{~mm}$.

\subsection{Ensaios Metalográficos}

Realizou-se a análise metalográfica dos metais de solda, consistindo de macrografiae microscopia eletrônica de varredura. A preparação das amostras consistiu da técnica convencional de lixamento e polimento, seguido de ataque químico com reagente nital $10 \%$ para a macrografia e $2 \%$ para a micrografia.

As microestruturas foram avaliadas nas regiões colunares e reaquecidas dos metais de solda, nas condições de como soldado (CS) e após tratamento térmico (TTPS), onde as regiões analisadas corresponderam à área do entalhe Charpy-V e do último passe.

\section{RESULTADOS E DISCUSSÃo}

Zang e Farrar [17] citam que a interação entre diversos elementos de liga em um metal de solda é uma análise complexa pelo efeito de sinergia entre eles. Particularmente, a interação entre os elementos níquel e manganês tem sido objeto de diversos estudos [17-23], devido ao seu efeito na tenacidade ao impacto de metais de solda de alta resistência. Neste aspecto, Bhadeshia [23] comenta que embora seja conhecido o efeito benéfico do níquel em aços ligados, o mesmo nem sempre se repete em metais de solda de alta resistência. Nestes casos, o aumento do teor de níquel pode provocar uma deterioração da tenacidade ao impacto. Desta forma, conclui que para manutenção de boa tenacidade é necessário balancear o aumento do teor do níquel com a redução do teor de manganês de forma a manter uma microestrutura adequada.

\subsection{Resistência Mecânica}

A Tabela 2 mostra a composição química dos metais depositados, onde se nota que os metais depositados $A$, B e C apresentam composição química similar em termos de $\mathrm{Ni}$ e $\mathrm{Mn}$, com pequena variação do $\mathrm{Mn}$. Embora seja de conhecimento geral o efeito deste último elemento no aumento da resistência mecânica de metais de solda

\footnotetext{
* Contribuição técnica ao $69^{\circ}$ Congresso Anual da ABM - Internacional e ao 14ํㅡㄹ ENEMET - Encontro Nacional de Estudantes de Engenharia Metalúrgica, de Materiais e de Minas, 21 a 25 de julho de 2014, São Paulo, SP, Brasil.
} 


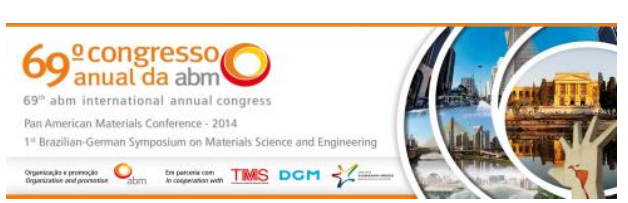

de alta resistência, deve-se destacar a importância da mudança do carbono equivalente dos metais de solda, o que interfere tanto nos resultados de resistência à tração (Tabela 3) quanto de dureza (Figura 2), resultados estes concordantes com diversos estudos disponíveis na literatura que afirmam existir uma boa relação entre o carbono equivalente e a resistência mecânica [15,24-26].

A única exceção é o consumível $\mathrm{D}$, que apresenta teores de $\mathrm{Mn}$ e Ni diferentes dos demais, sendo de destaque o elevado teor de $\mathrm{Mn}$, da ordem de 1,86\%. Neste aspecto, é importante citar os estudos de Kang et al. [18], Harrison et al. [19] e Surian et al. [27], que ressaltam que o Mn exerce um efeito muito mais potente que o $\mathrm{Ni}$ na resistência mecânica. Particularmente já foi observado em trabalho anterior [18] um efeito 5X maior do $\mathrm{Mn}$ em relação ao Ni.

Tabela 3. Resultados dos ensaios de tração dos metais de solda $\left({ }^{*}\right)$.

\begin{tabular}{c|c|c|c|c|c}
\hline Metal de Solda & Condição & LE (MPa) & LR (MPa) & Al (\%) & RA (\%) \\
\hline A & CS & 631 & 690 & 22,06 & 61,12 \\
\hline B & TTPS & 580 & 673 & 24,69 & 63,18 \\
\hline CS & 659 & 744 & 25,71 & 65,48 \\
\hline C & TTPS & 640 & 742 & 22,86 & 66,51 \\
\hline CS & 717 & 775 & 12,00 & 31,00 \\
\hline D & TTPS & 668 & 759 & 22,00 & 58,00 \\
\hline & CS & 743 & 827 & 18,29 & 62,00 \\
\hline & TTPS & 710 & 806 & 23,71 & 58,00
\end{tabular}

Nota: CS- como soldado; TTPS- Tratamento Térmico Pós-Soldagem.

(*) Valor médio de 2 ensaios

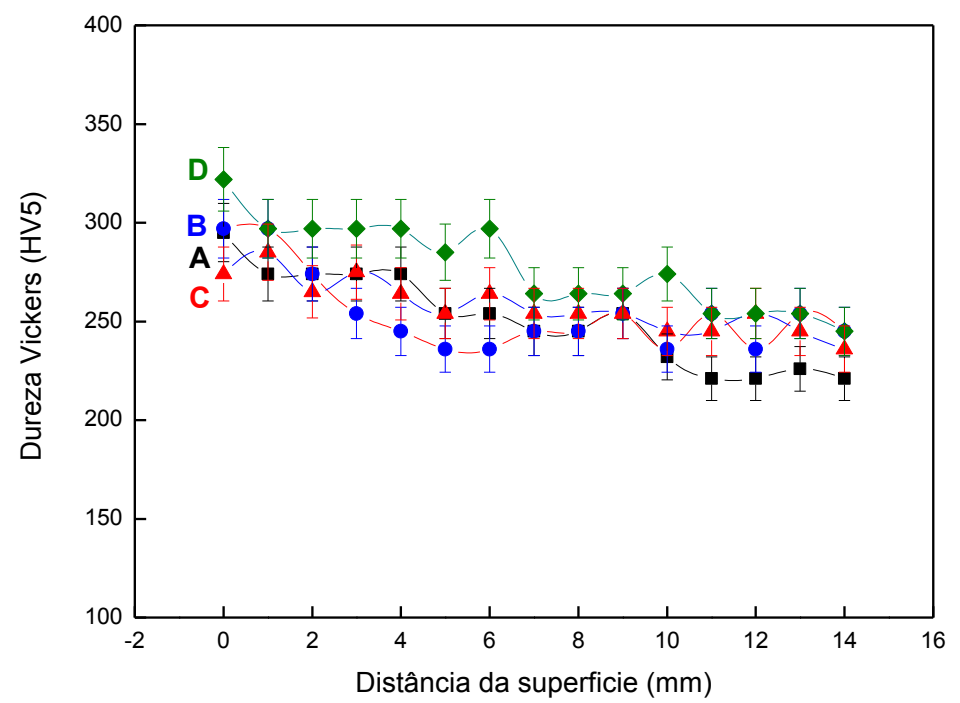

Figura 2. Resultados dos ensaios de dureza Vickers (HV5) para os metais de solda na condição de como soldado.

Todas estas evidências acima descritas, parecem ter importância no comportamento da resistência mecânica comparativa encontrada no presente trabalho e, adicionalmente, deve-se citar o fato que os valores obtidos estão de acordo com os dados da literatura para metais de solda similares em relação ao carbono equivalente, conforme mostrado na Figura 3.

Jorge et al. [15] em trabalho sobre metal de solda de alta resistência, citam que a maioria dos trabalhos que envolvem o efeito de tratamentos térmicos pós-soldagem na resistência mecânica de metais de solda [11-13,27-33], relatam uma queda desta

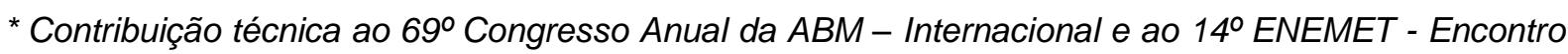
Nacional de Estudantes de Engenharia Metalúrgica, de Materiais e de Minas, 21 a 25 de julho de 2014, São Paulo, SP, Brasil. 


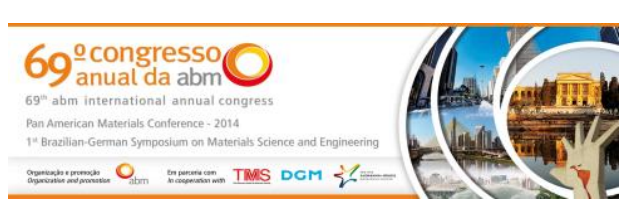

propriedade com a execução destes tratamentos. No entanto, destacam que no caso de metais de solda de mais alta resistência, existe uma tendência para que a diferença seja cada vez mais reduzida $[9,11,13,15]$, o que provavelmente está associado com o fato da microestrutura da região reaquecida apresentar a mesma microestrutura da região colunar, o que interfere na composição percentual da resistência do corpo-de-prova utilizado para o ensaio de tração representativo da qualificação do metal de solda [34,35]. Isto também foi verificado para os metais de solda dos estudos realizados, pois a consulta à Tabela 2 mostra a pequena diferença para a resistência mecânica para os diversos resultados obtidos entre as condições de como soldado e após TTPS, sendo a maior variação de apenas 3\%.

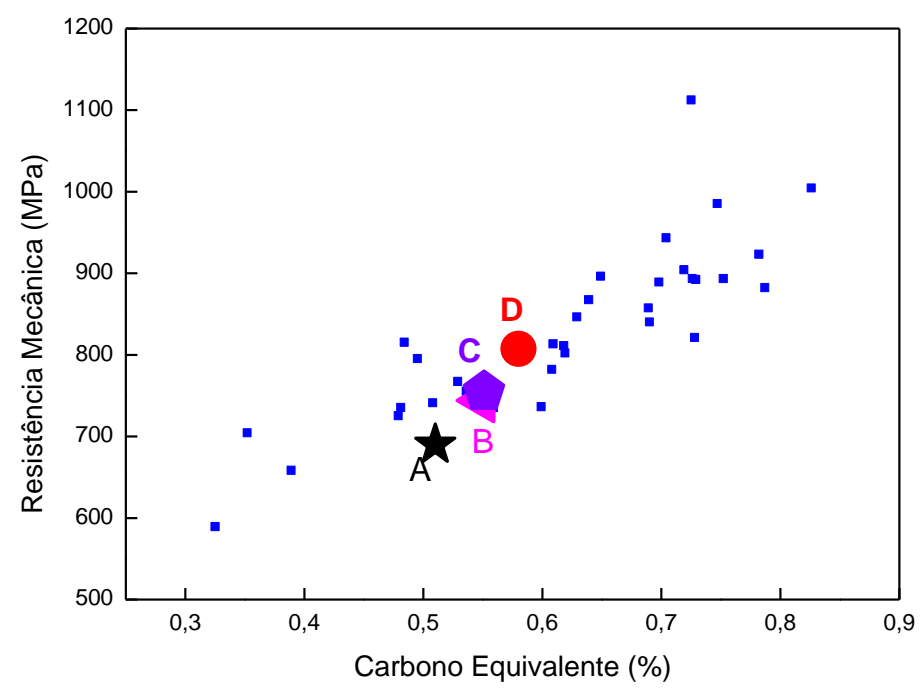

Figura 3. Variação da resistência mecânica com o carbono equivalente segundo diversos autores $[9,11,12,15,24,25]$

\subsection{Relação Tenacidade X Microestrutura}

Zang et al [17] estudaram o efeito do Ni na tenacidade ao impacto em função do teor de $\mathrm{Mn}$, observando que para baixos teores de $\mathrm{Mn}$, o Ni pouco afeta a tenacidade ao impacto. Já para $1,6 \% \mathrm{Mn}$, o $\mathrm{Ni}$ parece ter efeito decisivo na tenacidade, pois promove alterações microestruturais importantes, tais como segregações que tem efeito fundamental na tenacidade ao impacto. Kang et al. [18] também observaram este tipo de segregação, corroborando com a afirmação de Zang et al. [17] para a contribuição da mesma na redução da tenacidade ao impacto para maiores teores de $\mathrm{Ni}$, e associaram esta ocorrência ao teor de carbono do metal de solda. No entanto, quando se compara os resultados destes autores $[17,18]$, nota-se que mesmo sem a ocorrência de segregação, o metal de solda com $2,88 \% \mathrm{Ni}$ deste último estudo apresenta tenacidade ao impacto inferior, o que permite inferir que existem outros fatores interferindo nesta propriedade. De fato, verifica-se que efeitos microestruturais e mesmo o processo de soldagem, muitas vezes colocados como fundamentais para serem os controladores da tenacidade ao impacto, devem ser vistos com reservas, devendo ser avaliados os efeitos conjuntos de todos os fatores envolvidos na análise antes de uma conclusão final. Isto foi verificado por Kang et al [18] que mesmo para a soldagem com arame tubular do tipo metal cored com teor de níquel da ordem de 6,95\%, obtiveram valores de tenacidade elevados quando mantiveram o teor de Mn baixo, o mesmo acontecendo com Keehan [21,22] para a soldagem com eletrodos revestidos, ao variar somente o teor de $\mathrm{Mn}$ de 2,0\%

\footnotetext{
* Contribuição técnica ao $69^{\circ}$ Congresso Anual da ABM - Internacional e ao 14ํㅡㄹ ENEMET - Encontro Nacional de Estudantes de Engenharia Metalúrgica, de Materiais e de Minas, 21 a 25 de julho de 2014, São Paulo, SP, Brasil.
} 


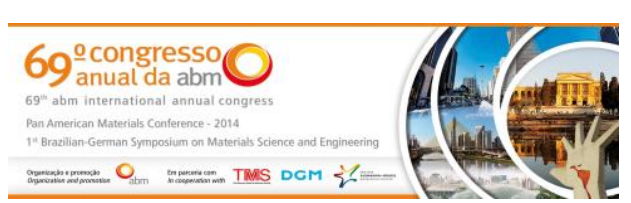

para $0,6 \%$. Neste aspecto, a observação da Figura 4 mostra a variação da tenacidade ao impacto com o teor de Mn para um metal de solda de alta resistência com $1,95 \% \mathrm{Ni}$, onde se nota que acima de $1,40 \% \mathrm{Mn}$, considerado o teor ótimo deste elemento para aços C-Mn [36], a tenacidade ao impacto sofre uma redução significativa [27]. De maior importância no escopo do presente trabalho, é notar que o consumível $\mathrm{D}$ é o único que apresenta um teor de $1,86 \% \mathrm{Mn}$, o que pode estar sendo um importante fator na menor tenacidade deste metal de solda. De fato, esta mesma evidência já foi motivo de observações similares também em outros trabalhos técnicos [9,11], onde se notou que a tentativa do aumento do teor de Mn para melhoria da resistência mecânica, provocou uma redução da tenacidade ao impacto, mesmo com menores teores de Ni.

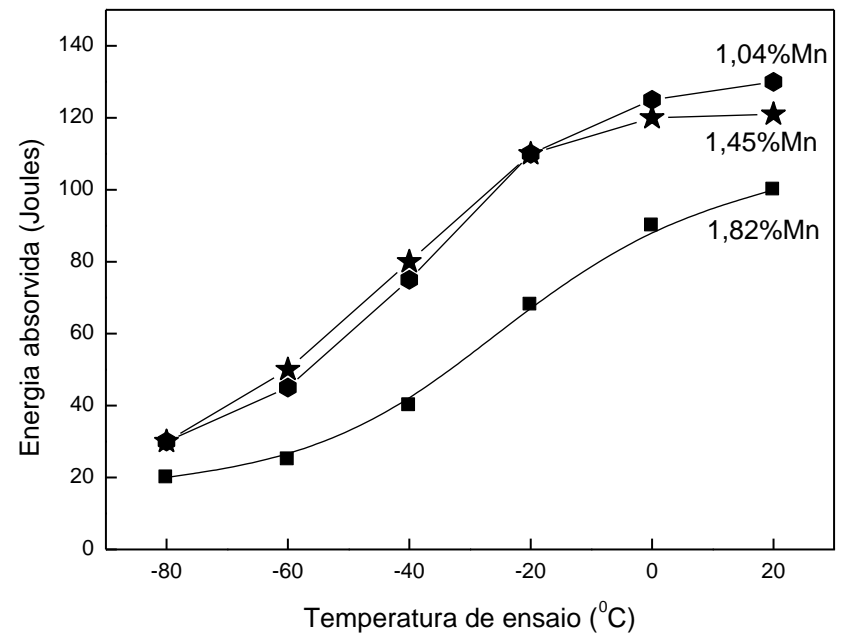

Figura 4. Efeito do $\mathrm{Mn}$ na tenacidade ao impacto de metal de solda de alta resistência (C-0,04, Si$0,30, \mathrm{Ni}-1,95, \mathrm{Mo}-0,35)[27]$.

As evidências apresentadas anteriormente estão de acordo com os resultados obtidos no presente trabalho, pois a observação da Figura 5 permite verificar que os metais de solda A, B e C apresentam tenacidade ao impacto próximas, por possuírem teores de $\mathrm{Ni}$ similar e teor de $\mathrm{Mn}$ de 1,0\% (metal de solda A) e em torno de $1,4 \%$ (metais de solda $B$ e $C$ ), enquanto que o metal de solda $D$ apresentou uma valor inferior a todos os outros.

Uma análise comparativa mais detalhada, mostra também haver coerência nos resultados, visto a predominância da microestrutura constituída por ferrita com segunda fase nos metais de solda estudados, como evidenciado pela análise metalográfica (Figura 6). Segundo a literatura [34,35,38], o aumento do carbono equivalente propicia a predominância de produtos de baixa temperatura de transformação, sendo que para as taxas de resfriamento normais de soldagem, a microestrutura normalmente encontrada é constituída de martensita e bainita, com acréscimo do percentual do primeiro constituinte com o aumento do carbono equivalente. Adicionalmente, cabe destacar que dependendo do percentual de cada constituinte haverá mudança nas propriedades mecânicas do metal de solda [40]. Estas afirmações dão suporte à análise dos resultados obtidos no presente trabalho, pois o metal de solda $D$, que apresenta o maior valor de carbono equivalente (Tabela 2) mostra uma microestrutura com elevado percentual de constituintes A-M e a ocorrência de martensita, para o mesmo preaquecimento dos outros metais de

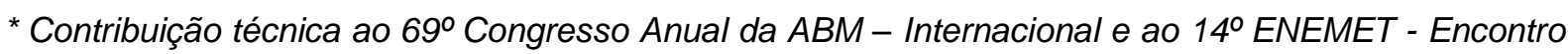
Nacional de Estudantes de Engenharia Metalúrgica, de Materiais e de Minas, 21 a 25 de julho de 2014, São Paulo, SP, Brasil. 


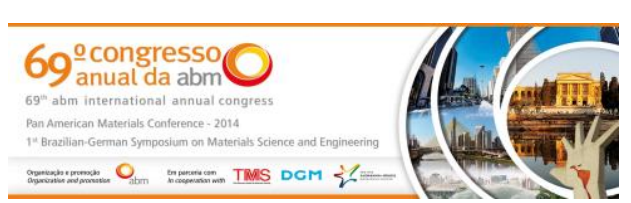

solda, sendo todos estes fatores importantes para a contribuição de uma menor tenacidade [31,37,39], como foi observado.

Finalmente, deve ser destacado que, contrariamente ao que foi verificado para a resistência mecânica não parece haver uma relação precisa da tenacidade ao impacto com o carbono equivalente, o que já foi observado por outros autores [25,26]. Segundo Farrar et al. [41], o TTPS pode causar um efeito nocivo na tenacidade devido à precipitação de carbetos nos contornos de grão. Algumas publicações recentes envolvendo metais de solda de alta resistência, tem mostrado que quando se observa a existência de uma rede contínua de precipitação ao longo do contorno de grão da austenita prévia (decoramento de contorno), a tenacidade experimenta uma redução acentuada após o TTPS [12,13,42,43].

A análise microestrutural conduzida por microscopia eletrônica de varredura (Figura 6), permitiu evidenciar que o TTPS, embora tivesse propiciado a decomposição dos constituintes A-M e o revenimento da microestrutura, também gerou a precipitação de carbetos nos contornos de grão da austenita prévia dos metais de solda B,C e D, o que causou a queda da tenacidade destes metais de solda após o TTPS.

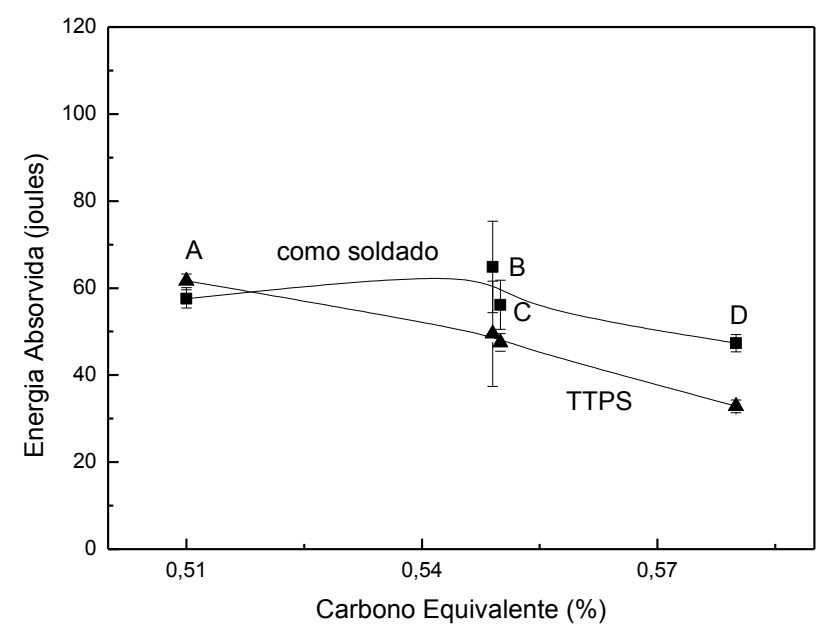

Figura 5. Variação da energia absorvida à $-20^{\circ} \mathrm{C}$ com o carbono equivalente, em Joules.

\subsection{Avaliação Geral dos Resultados}

O presente trabalho dá continuidade à um programa de pesquisa que tem por objetivo avaliar consumíveis adequados para soldagem de aços utilizados em componentes de sistemas de ancoragem, que atendam os requisitos da norma IACS W22 [1]. No caso presente, a análise visou metais de solda produzidos pelo processo arame tubular, de modo a melhorar a produtividade, devendo ser ressaltado que nesta aplicação a execução do TTPS é mandatória $[5,28]$.

A avaliação do comportamento das propriedades mecânicas dos metais de solda estudados, mostrada de forma comparativa na Figura 7, evidencia o efeito da composição química nestas propriedades, pois se verifica que o metal de solda $A$, embora apresentando a melhor tenacidade de todos os estudados, não possui um nível de resistência mecânica adequada para a aplicação em questão, provavelmente devido ao seu baixo teor de Mn. Por outro lado, o metal de solda D apresenta comportamento inverso, com alta resistência e baixa tenacidade, devido à ocorrência de martensita e aumento significativo de constituintes $A-M$, o que

* Contribuição técnica ao $69^{\circ}$ Congresso Anual da ABM - Internacional e ao 14ํㅡㄹ ENEMET - Encontro Nacional de Estudantes de Engenharia Metalúrgica, de Materiais e de Minas, 21 a 25 de julho de 2014, São Paulo, SP, Brasil. 


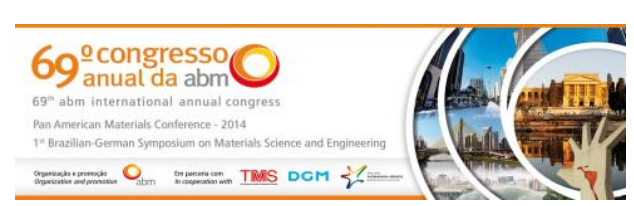

caracteriza que uma composição com alto Mn também não é apropriada, tendo sido verificado neste caso uma redução adicional da tenacidade após TTPS devido à intensa precipitação de carbetos em contornos de grão (Figura 6).

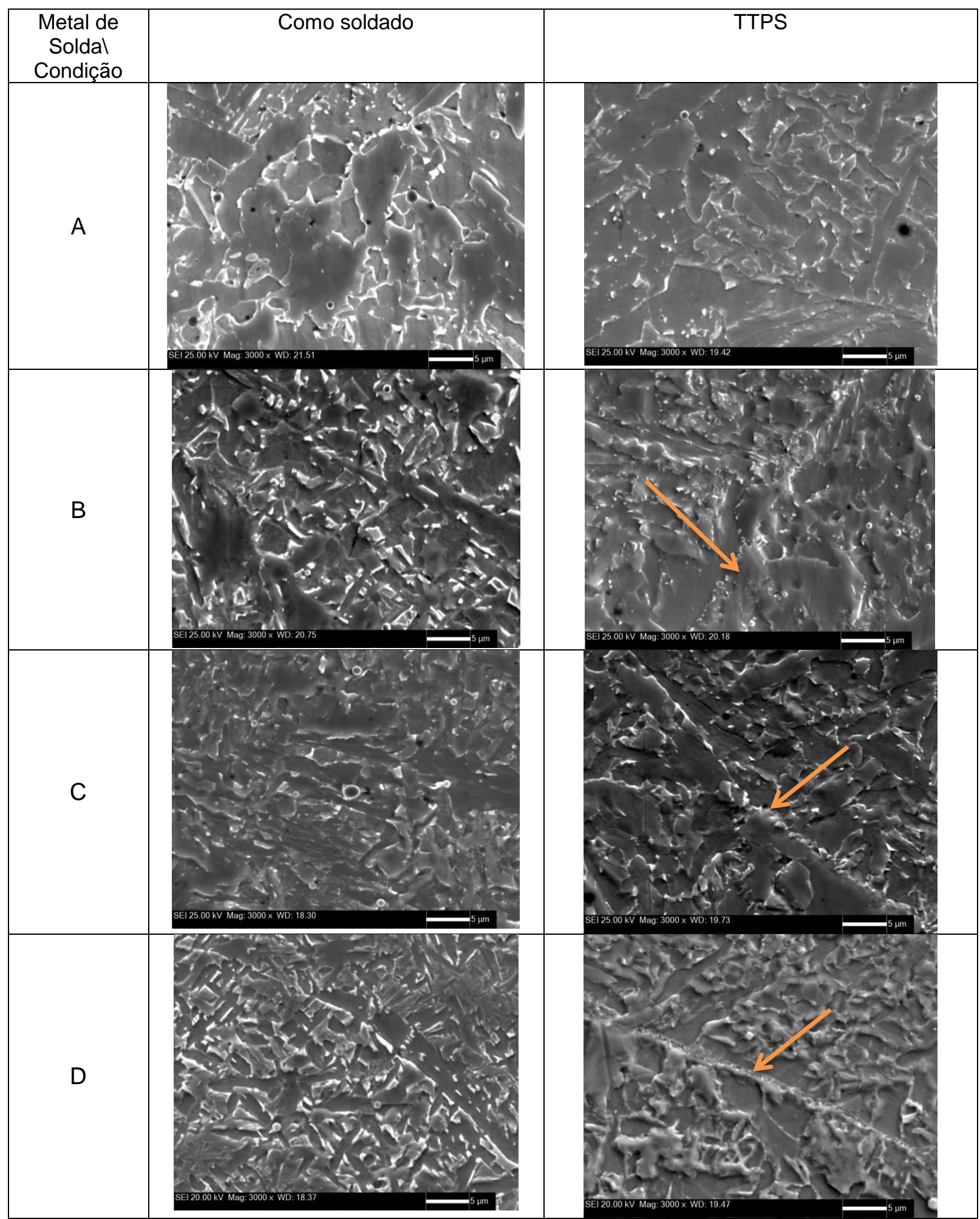

Figura 6. Microestrutura da região do entalhe do corpo-de-prova Charpy-V dos metais de solda. Aumento: 3000X. Ataque: Nital 2\%

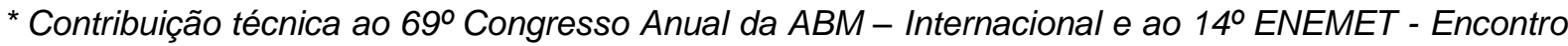
Nacional de Estudantes de Engenharia Metalúrgica, de Materiais e de Minas, 21 a 25 de julho de 2014, São Paulo, SP, Brasil. 


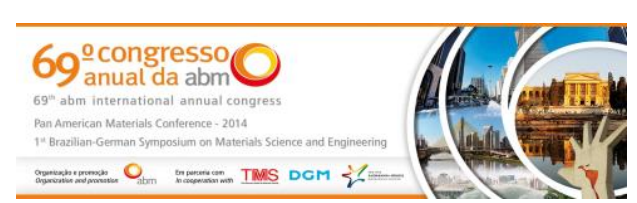

\section{REFERÊNCIAS}

1 International Association of Classification Societies, W22, Offshore Mooring Chain, June, 2011.

2 AWS 5.5, Specification for low alloy steel electrodes for shielded metal arc welding, 1996.

3 AWS 5.28, Specification for low alloy steel electrodes and rods for gas shielded arc welding, 1996.

4 Military Specification - MIL-S-16216K, 1987, "Steel Plate, Alloy, Structural, High Yield Strength (HY-80 and HY-100)", Departament of Defense, United States of America.

5 Jorge JCF et al. Desenvolvimento de procedimento de reparo por soldagem de amarras de aço para ancoragem de plataformas de petróleo, Anais do XXVII Congresso Nacional de Soldagem , 2001, p.1-10.

6 MIL 22200-1F, Electrodes, welding, mineral covered, iron-powder, low hydrogen medium and high tensile steel, as welded or stress-relieved weld application, 1981.

7 Sumam JA, Jorge JCF, Souza LFG e Bott IS. Efeito de tratamentos térmicos póssoldagem nas propriedades de aço fundido de elevada resistência para sistemas de ancoragem de plataformas marítimas, Soldagem \& Inspeção, 2004; 9(4): 205-212.

8 Jorge JCF, Souza LFG, Santos Filho OR, Santos Filho AMF, Bott IS e Guimarães FHB. Relação tenacidade/microestrutura da ZTA de aço fundido ASTM A 148 GR. 8050 para acessórios de ancoragem de plataformas de petróleo, Soldagem \& Inspeção, 2004; 9(4): 192-197.

9 Jorge JCF; Souza LFG; Santos Filho OR; Santos Filho AMF e Bott IS. Influência da composição química e tratamento térmico pós-soldagem nas propriedades mecânicas e microestruturais de metais de solda de alta resistência, Anais do XXXIII Congresso Nacional de Soldagem, 2007; 1-10.

10 Farneze HN; Jorge JCF; Souza LFG; Bott IS. Estudo comparativo de metais de solda de aço de alta resistência obtidos pelos processos eletrodo revestido e arame tubular para aplicação em equipamentos de amarração offshore; Soldagem \& Inspeção, 2009; 14(2):151-160.

11 Jorge JCF, Souza LFG, Santos Filho OR e Bott IS. Estudo de metais de solda de aço de extra alta resistência para utilização em componentes de ancoragem de plataformas de petróleo. Parte I: Propriedades Mecânicas, Anais do XXXVII CONSOLDA, 2011; 1 10.

12 Vogas PVBD et al. Efeito do tratamento térmico pós-soldagem nas propriedades de metal de solda de alta resistência obtidos por arame tubular tipo flux cored, Anais do $67^{\circ}$ Congresso Internacional da ABM, 2012;374-387.

13 Gomes AJM et al. Estudo comparativo de metais de solda de aços de extra alta resistência para utilização em componentes de linhas de ancoragem de plataformas de petróleo, Anais do $67^{\circ}$ Congresso Internacional da ABM, 2012;806-818.

14 Pinheiro MM et al. Efeito do tratamento térmico pós-soldagem nas propriedades de metal de solda de alta resistência obtidos por arame tubular tipo metal cored, Anais do $67^{0}$ Congresso Internacional da ABM, 2012:1323-1333.

15 Jorge JCF, Faragasso SM, Souza LFG e Bott IS, Efeito do Tratamento Térmico PósSoldagem nas Propriedades Mecânicas e Microestruturais de Metal de Solda de Aço de Extra Alta Resistência para Utilização em Equipamentos de Ancoragem, Soldagem e Inspeção, 2013; 18 (2): 137 - 148.

16 ASTM A-370-07a; Standard Test Methods and Definitions for Mechanical Testing of Steel Products. ASTM International.

17 Zhang Z, Farrar RA. Influence of $\mathrm{Mn}$ and Ni on the Microstructure and Toughness of CMn-Ni Weld Metals, Welding Journal, 1997; 76(5):183-196.

18 Kang BY, Kim HJ e Hwang SK, Effect of Mn and Ni on the variation of the microstructure and mechanical properties of low-carbon weld metals, ISIJ International, 2000;40(12):1237-1245.

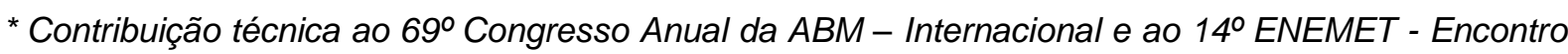
Nacional de Estudantes de Engenharia Metalúrgica, de Materiais e de Minas, 21 a 25 de julho de 2014, São Paulo, SP, Brasil.
} 


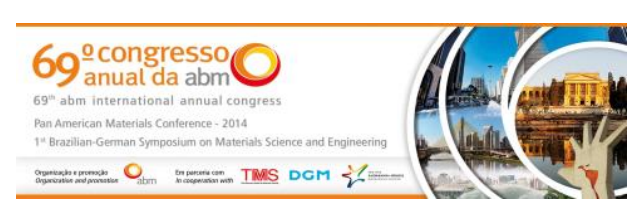

19 Harrison PL, Farrar RA. Microstructural and toughness of C-Mn and C-Mn-Ni weld metals. Part 1: Microstructural development, Metal Construction, 1987; 19(7): 392R-399R.

20 Trindade VB; Paranhos RPR; Payão JC e Souza LFG. Influência da adição de níquel na tenacidade de metais de solda de aços C-Mn antes e após tratamento térmico de alívio de tensões, Soldagem \& Inspeção; 2005; 10(4):164-171.

21 Keehan E, Karlsson L, Andrén HO. Influence of C, Mn and Ni contents on microstructure and properties of strong steel weld metals, Part I - Effect of nickel content, Science and Technology of Welding and Joining, 2006;11(1):1-8.

22 Keehan E, Karlsson L, Andrén HO. Influence of $\mathrm{C}, \mathrm{Mn}$ and Ni contents on microstructure and properties of strong steel weld metals, Part II - Impact toughness gain from manganese reductions, Science and Technology of Welding and Joining, 2006;11(1): 9-18.

23 Bhadeshia HKDH. Strong ferritic-steel welds, Materials Science Forum, 2007; 539-543: 6-11.

24 Surian E, Rissone NM, Svoboda HG and Vedia LA. SMAW, FCAW and SAW HighStrength Ferritic Deposits: The Challenge Is Tensile Properties, Welding Journal, 2010; 89(3):54-64s.

25 Ramirez JE. Examining the Mechanical Properties of High-Strength Steel Weld Metals, Welding Journal, 2009; 88(1):32-38.

26 Talas S. The assessment of carbon equivalent formulas in predicting the properties of steel weld metals, Materials \& Design, 2010; 31:2649-2653.

27 Surian E, Trotti J, Cassanelli AN e de Vedia LA, Influence of Mn content on mechanical properties and microstructure of a high strength SMA electrode weld metal, 1987, IIWIIS Doc. II-A-724-87.

28 Jorge JCF et al. Desenvolvimento de procedimento de reparo por soldagem de amarras de aço para ancoragem de plataformas de petróleo - Parte II - Homologação do Procedimento, Anais do XXVIII Congresso Nacional de Soldagem , 2002; São Paulo, p. 1-10.

29 Evans GM. Development of MMA electrodes for offshore application, Metal Construction, 1983; 15(7):438-443.

30 Surian ES, Trotti J, Cassanelli A, Vedia LA. Influence of chromium element on mechanical properties and microstructure of weld metal from a high strength SMA electrode, Welding Journal, 1994; 73(3):45s-53s.

31 Jorge JCF, Rebello JMA e Souza LFG. The effect of chromium on the microstructure/toughness relationship of C-Mn weld metal deposits, Materials Characterization, 2001; 47(3/4):195- 205.

32 Jorge JCF, Rebello JMA. Influence of welding procedure on the microstructure and toughness of high strength ferritic steel weld metals, Revue de la Soudure, 2000; 56(1):4-12.

33 Vieira LA. Avaliação da tenacidade após tratamento térmico de alívio de tensões em soldas produzidas com arames tubulares rutílicos que contenham níquel. [Dissertação de Mestrado], Belo Horizonte, Escola de Engenharia, Universidade Federal de Minas Gerais, 2006.

34 Ramirez JE. Characterization of high strength steel weld metals, chemical composition, microstructure and nonmetallic inclusions, Welding Journal, 2008; 87(3):65s-75s.

35 Svensson LE. Consumables for Welding High Strength Steels, Svetsaren, 1999;54 (1-2): 29-33.

36 Evans GM. Effect of manganese on the microstructure and properties of all-weld metal deposits. Welding Journal, 1980; 59 (3): 67-s-75-s.

37 Paranhos RPR. Relação tenacidade/microestrutura de metal de solda de aço baixo C-Mn obtido por arco submerso em soldas multipasse, Anais do $10^{\circ}$ Encontro Nacional de Tecnologia da Soldagem; 1984; Vitória, Brasil. São Paulo: Associação Brasileira de Soldagem: 95-116.

\footnotetext{
* Contribuição técnica ao 69ำ Congresso Anual da ABM - Internacional e ao 14ํㅡㄹ ENEMET - Encontro Nacional de Estudantes de Engenharia Metalúrgica, de Materiais e de Minas, 21 a 25 de julho de 2014, São Paulo, SP, Brasil.
} 


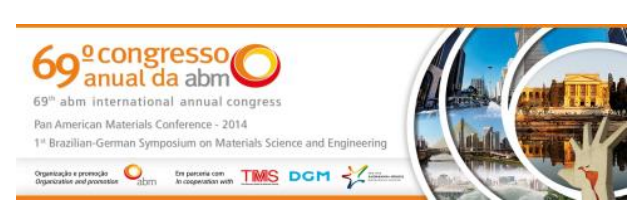

38 Lord M, Jennings G. Effect of interpass temperature on properties of high-strength weld metals, Svetsaren, 1999;54(1-2): 53-58.

39 Souza LFG, Jorge JCF, Payão Filho JC. Microestrutura e tenacidade ao impacto de metais de solda de aços C-Mn-Ni obtidos por soldagem com arco submerso, Anais do XXII Encontro Nacional de Tecnologia da Soldagem, 1996, Blumenau, p.35-47.

40 Karlsson L, Keehan E, Andren HO, Bhadeshia HKDH. Development of high strength steel weld metals -potential of novel high-Ni compositions, Proc. Of the Eourojoin 5, 2004, Viena: 1-8.

41 Farrar RA, Taylor LG, Harrison EM. Effect of stress-relieving on fracture properties of submerged arc welds of C-Mn steels, Metals Technology, 1989;10: 380-389.

42 Gomes AJM, Jorge JCF, Souza LFG, Bott IS. Influence of Chemical Composition and Post Welding Heat Treatment on the Microstructure and Mechanical Properties of

43 Salvador LSF e Jorge JCF. Avaliação de consumíveis para soldagem de risers de completação, 1994; Anais do 2 Simpósio Latino Americano sobre Tubulações e Vasos de Pressão, 1994, Gramado:315-324.

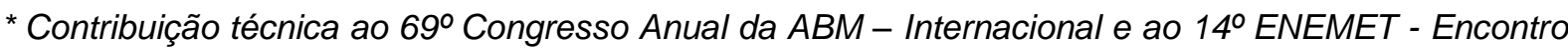
Nacional de Estudantes de Engenharia Metalúrgica, de Materiais e de Minas, 21 a 25 de julho de 2014, São Paulo, SP, Brasil. 